\title{
Surgical management of choledocal cyst in different techniques: a 4-year experience
}

\begin{abstract}
Objective: The aim of this study was to evaluate the efficacy and complications of different techniques in the treatment of choledochal cyst in children.

Materials and methods: Data was collected retrospectively from 32 patients with choledocal cyst (type I), managed in the Department of Pediatric Surgery, Dhaka Medical College and Hospital (DMCH), Dhaka, Bangladesh conducted during the period of January 2015 to December 2018. Roux-en-Y hepatico-jejunostomy, Hepatico-duodenostomy, Choledocho-cholecysto-duodenostomy, Hepatico-jejunostomy done in 9, 14, 3 and 6 patients respectively.
\end{abstract}

Results: There were 8 males and 24 females. The age of patients at diagnosis varied from 13 months to 12 years (mean age 71.9 months). The early postoperative complication rate after cyst excision and biliary reconstruction was $12.5 \%$ (4 of 32). One patient in each type $(1 / 9,1 / 14,1 / 3,1 / 6)$ of operation developed an anastomotic leakage and there was no mortality.

Conclusions: Hepatico-duodenostomy is an acceptable technique in the management of choledocal cyst as it's a simple, quick technique and being more physiological with maintaining normal anatomy in attaining biliary drainage.

Keywords: roux-en-Y hepatico-jejunostomy, hepatico-duodenostomy, choledochocholecysto-duodenostomy, hepatico-jejunostomy, choledocal cyst
Volume 8 Issue 3 - 2020

Sahadeb Kumar Das,' Kaniz Hasina, ${ }^{2}$ Ashraf Ul Huq, ${ }^{2}$ Abdul Hanif, ${ }^{2}$ Mohammed Shadrul Alam, ${ }^{2}$ Jaglul Gaffer Khan ${ }^{3}$

'Assistant Professor, Department of Pediatric Surgery, Khulna Medical College, Khulna, Bangladesh

${ }^{2}$ Professor, Department of Pediatric Surgery, Dhaka Medical College, Dhaka, Bangladesh

${ }^{3}$ Associate Professor, Department of Pediatric Surgery, Dhaka Medical College, Dhaka, Bangladesh

Correspondence: Dr. Sahadeb Kumar Das, Assistant Professor, Department of Pediatric Surgery, Khulna Medical College, Khulna, Bangladesh, Tel 8801710894635 ,

Emaildrsdask8@gmail.com

Received: May 17, 2020 | Published: August 26, 2020
Abbreviations: DMCH, Dhaka medical college and hospital; APBJ, anomalous pancreaticobiliary junction; POD, postoperative day

\section{Introduction}

Choledocal cysts are rare congenital anomalies of the biliary tract characterized by dilatation of either intra or extrahepatic biliary tract or both. These cysts are uncommon in Western countries, but are not rare in Bangladesh. Among the five types of Choledochal cysts, type I cysts are the most common types, which are associated with anomalous pancreaticobiliary junction (APBJ). Complete excision of the cyst and bilioenteric anastomosis is the treatment of choice in choledochal cyst. Biliary reconstruction after complete excision of the cyst can be done by various techniques. Roux-en-Y hepatico-jejunostomy or hepaticoduodenostomy is the most commonly performed operations. Rouxen-Y hepatico-jejunostomy is a classical procedure that involves two anastomosis with a significant late complications namely intestinal obstruction, anastomotic stricture and peptic ulcer., ${ }^{1,2}$ Hepaticoduodenostomy is another preferred technique as it more physiological and simpler to perform. ${ }^{3,4}$ Choledocho-cholecysto-duodenostomy is a new surgical technique that preserve the gall bladder and used as the biliary conduit. ${ }^{5}$ Hepatico-jejunostomy is latest technique. It requires complete excision of the cyst and anastomosis of hepatic duct with jejunum without Roux-en-Y limb. This newer technique requires less operation time. There is a debate regarding the optimal technique for biliary reconstruction. The aim of this study was to analyze the outcomes of our experience of 32 patients of choledocal cyst underwent various types of surgical procedures.

\section{Materials and methods}

It was a retrospective study of 32 patients with choledocal cyst (type I) managed in the Department of Pediatric Surgery, Dhaka Medical College and Hospital (DMCH), Dhaka, Bangladesh conducted during the period of January 2015 to December 2018. Roux-en-Y hepaticojejunostomy, Hepatico-duodenostomy, Choledocho-cholecystoduodenostomy, Hepatico-jejunostomy done in 9, 14, 3 and 6 patients respectively.

\section{Surgical technique}

Roux-en-Y hepatico-jejunostomy: After cyst excision in the usual technique, the jejunum approximately $20 \mathrm{~cm}$ from the ligament of Treitz was devided. The Roux limb was passed through a created window in the transverse colon to the sub-hepatic region and hepaticojejunostomy performed. Gastro-intestinal continuity was maintained by jejuno-jejunostomy in a end to side fashion.

Hepatico-duodenostomy: Following cyst excision in the standard technique, common hepatic duct was anastomosed with distal first part of duodenum.

Choledocho-cholecysto-duodenostomy: The choledocal cyst was excised in the usual method. This technique differs with others technique that gall bladder with its neck was kept in situ with preservation of cystic artery. The fundus and part of body of gall bladder was mobilized from the liver bed for it's easily access to first part of duodenum with the advantages of tension free anastomosis. The gall bladder neck was anastomosed with the common hepatic 
duct and fundus of gall bladder was anastomosed with the distal first part of duodenum.

Hepatico-jejunostomy: In this newest technique, the cyst was excised at first, then a loop of jejunum approximately $20-30 \mathrm{~cm}$ from the ligament of Treitz was brought out to sub-hepatic region in the way anterior to transverse colon. Anastomosis of the common hepatic duct with the side of jejunum was done in a end to side manner.

The presenting complaints, examination findings, investigations, treatment, operative details and postoperative courses were analyzed.
Follow up information was carried out during the post operative follow up in outpatients department. History was taken particularly to pain, cholangitis, features of gastritis and examined Table 1. Liver function test and abdominal imaging were done at three months after operation. Then the patients were followed up every six months interval. Outcomes evaluated included operation time, hospital stay and incidence of postoperative bile leak, cholangitis, reflux or gastritis, anastomotic stricture, bleeding, intestinal obstruction and reoperative rate. The statistical test applied was chi-square test. $\mathrm{P}$ value $<0.05$ was considered to statistically significant.

Table I Patients characteristics

\begin{tabular}{|c|c|c|c|c|}
\hline & $\begin{array}{l}\text { Roux-en-Y Hepatico- } \\
\text { jejunostomy }\end{array}$ & $\begin{array}{l}\text { Choledocho-cholecysto- } \\
\text { duodenostomy }\end{array}$ & $\begin{array}{l}\text { Hepatico- } \\
\text { duodenostomy }\end{array}$ & $\begin{array}{l}\text { Hepatico- } \\
\text { jejunostomy }\end{array}$ \\
\hline Number of patients & 9 & 14 & 3 & 6 \\
\hline $\operatorname{Sex}(M / F)$ & $2-7$ & $4-10$ & $\mathrm{I}-2$ & $1-5$ \\
\hline \multicolumn{5}{|l|}{ Age (Months) } \\
\hline Ranges & $\mid 8-144$ & $30-144$ & $18-84$ & $13-132$ \\
\hline Mean & 76 & 72.85 & 50 & 74.66 \\
\hline \multicolumn{5}{|l|}{ Presentation } \\
\hline Pain & 5 & 11 & 2 & 4 \\
\hline Jaundice & 4 & 6 & 2 & 3 \\
\hline Lump & 4 & 4 & I & 1 \\
\hline \multicolumn{5}{|l|}{ Investigation } \\
\hline USG & 9 & 14 & 3 & 6 \\
\hline $\mathrm{MRCP}$ & 5 & 7 & 3 & 3 \\
\hline \multicolumn{5}{|c|}{ Operation time (Minutes) } \\
\hline Range & $130-180$ & $85-110$ & $175-180$ & $90-120$ \\
\hline Mean & 164 & 95.78 & 177.66 & 100.66 \\
\hline Liver biopsy & 2 & 2 & 0 & 2 \\
\hline Peroperative findings & Cholelithiasis: 2 & Cholelithiasis: I & & Cholelithiasis: I \\
\hline \multicolumn{5}{|l|}{ Oral feeding } \\
\hline Usual & $4^{\text {th }} P O D$ & $4^{\text {th }} P O D$ & $4^{\text {th }}$ POD & $4^{\text {th }}$ POD \\
\hline Delayed & I $\left(6^{\text {th }} P O D\right)$ & I ( $8^{\text {th }}$ POD $)$ & I (I $\left.0^{\text {th }} P O D\right)$ & I ( $\left.7^{\text {th }} P O D\right)$ \\
\hline \multicolumn{5}{|l|}{ DT removal } \\
\hline Usual & $5^{\text {th }}$ POD & $5^{\text {th }}$ POD & $5^{\text {th }} P O D$ & $5^{\text {th }}$ POD \\
\hline Delayed & I ( $8^{\text {th }}$ POD) & I ( $8^{\text {th }}$ POD $)$ & I (I $2^{\text {th }}$ POD $)$ & I ( $8^{\text {th }}$ POD) \\
\hline \multicolumn{5}{|l|}{ Hospital stay (Days) } \\
\hline Range & $7-10$ & $6-9$ & $8-14$ & $7-9$ \\
\hline Mean & 8.33 & 7.57 & 10.33 & 7.83 \\
\hline \multicolumn{5}{|l|}{ Complications } \\
\hline Anastomotic leakage & I (II,II\%) & I (7.I4\%) & I (33.33\%) & I (16.66\%) \\
\hline \multirow[t]{2}{*}{ Late } & Adhesive pain:I & Bil. Gastritis: I & Adhesive pain:I & Cholangitis: I \\
\hline & & & Cholangitis:I & \\
\hline
\end{tabular}




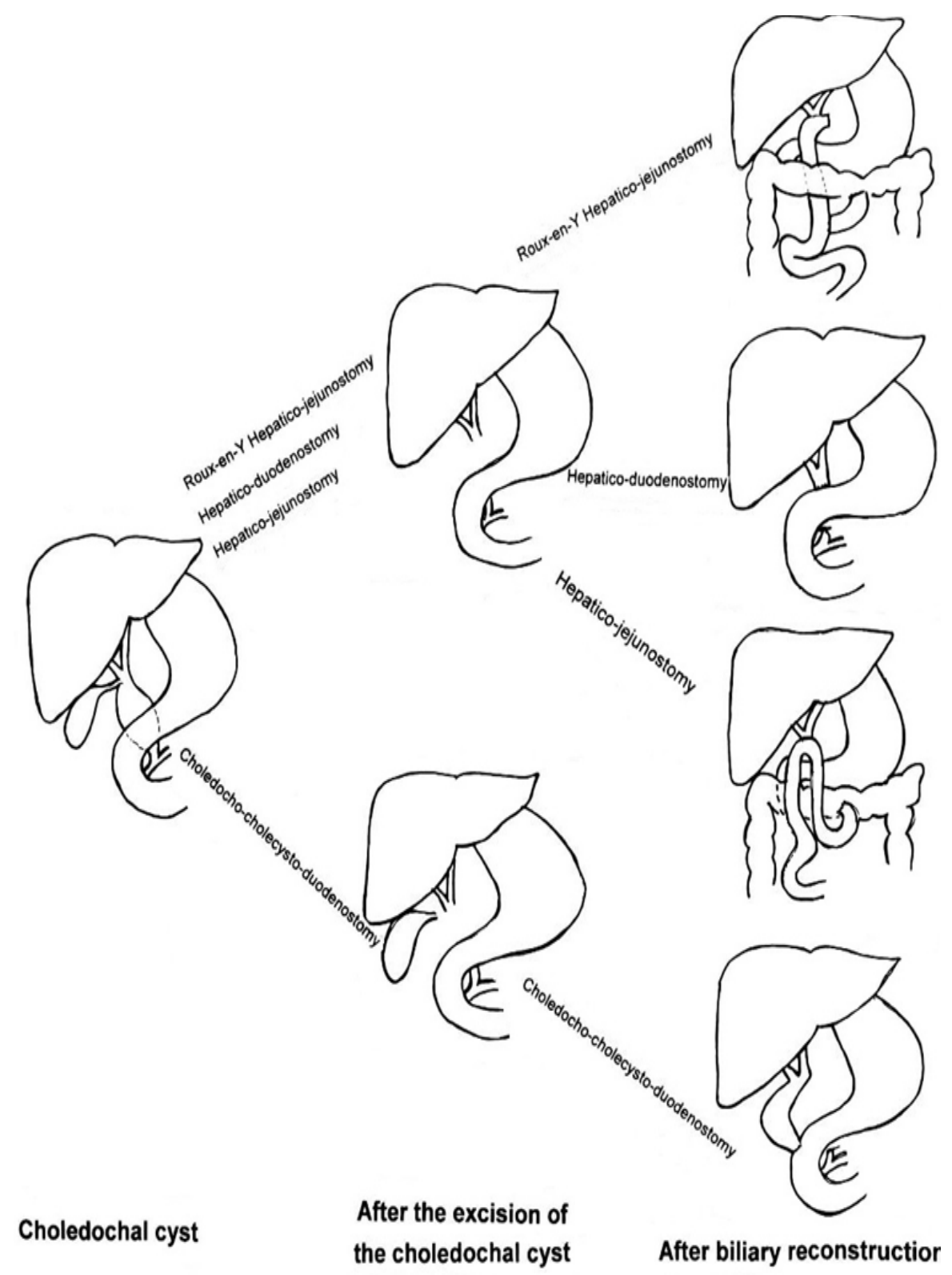

Figure I Diagrammatic presentation of different techniques of operation.

\section{Results}

There were 8 males and 24 females with a male: female ratio of $1: 3$. The age of patients at diagnosis varied from 13 months to 12 years (mean age 71.9 months). All patients had type I choledochal cysts, and were symptomatic on admission; presenting symptoms included pain in $22(68.7 \%)$, jaundice in $15(46.8 \%)$, lump in $10(31.2 \%)$. Among them, only 4 patients presented with the classical triad. In addition to ultra sonogram as an imaging studies, MRCP done in 18 patients for evaluating the biliary anatomy before planning operation. One patient of hepatico-duodenostomy had history of previous drainage due to pus formation. All patients' underwent complete excision of the cyst The mean duration of the operation time was 123.5 minutes (range 85 to 180 minutes). Usual oral feeding started on $4^{\text {th }}$ postoperative day (POD) but delayed on four patients who developed anastomotic leakage. The average time of drain removal was $5^{\text {th }}$ post operative day. In 4 cases of anastomotic leakage, drain tube were removed on $8^{\text {th }}$ POD in 3 patients but one patient of Choledocho-cholecystoduodenostomy who had progressive drainage of bile, drain tube was removed on $12^{\text {th }}$ POD. The average hospital stay was 8 days (range: 6-14 days). The early postoperative complication rate after cyst excision and biliary reconstruction was $12.5 \%$ (4 of 32 ) and there was no mortality. One child of Roux-en-Y hepatico-jejunostomy had a bile leak with features of peritonitis. One 3 years female patient of Hepatico-duodenostomy had a bile leak upto 7 days postoperatively and healed spontaneously. One patient of Choledocho-cholecystoduodenostomy was recovering well upto $7^{\text {th }}$ POD. After that, the patient developed abdominal distension with progressive drainage of bile through the drain tube and improved gradually. Another one patients of hepatico-jejunostomy had scanty bile leak that was healed spontaneously. 


\section{Discussion}

Still the choledocal cyst management is challenging. Surgical treatment was carried out with total excision of the cyst, cholecystectomy and bilio-enteric reconstruction. The bilioenteric bypass can be fashioned in different techniques. Roux-en-Y Hepatico-jejunostomy has been accepted as classical procedure in treating choledocal cyst. ${ }^{6}$ This technique requires longer operation time with two anastomosis. Several studies have reported some early and late post operative complications of this procedure including anastomotic leakage, cholangitis, anastomotic stricture, twisted loop and biliary stone formation. ${ }^{7,8}$ In this study, one patient of Roux-en-Y Hepatico-jejunostomy had anastomotic leakage and on follow up, one patient developed mild adhesive abdominal pain without features of cholangitis. Hepatico-duodenostomy has reported as an alternative technique of Roux-en-Y Hepatico-jejunostomy solves some of these complications and accepted as a more physiological procedure. ${ }^{3,9}$ Maximum number of patients $(43.75 \%)$ in this series underwent hepatico-duodenostomy and one patient has mild leakage in the early postoperative period. Till date, overall complications rate are low and comparable to other center. ${ }^{3}$ Choledocho-cholecysto-duodenostomy is a new technique introduced by an author that uses native biliary channel for bile drainage instead of intestinal conduit. No significant early complications have been observed in the new technique. No late follow up mentioned but noted that anastomotic leakage, anastomotic stricture, biliary fistula, reflux, recurrent cholangitis, gall stones, carcinoma of gall bladder may developed in the late postoperative period. ${ }^{5}$

Hepatico-jejunostomy without Roux-en-Y reconstruction is a newest technique practiced in our center. It requires shorter time. One patient in this group experienced scanty biliary leakage in the early postoperative period that was healed spontaneously. This technique developed with the possibilities of reflux cholangitis, kinking of anastomotic jejunal loop. To date, after a mean follow up of 19.9 months, no significant complications noticed. Another important advantage is that this operation can be converted into Roux-en-Y Hepatico-jejunostomy or Hepatico-duodenostomy in later if needed. Liver biopsy was done in 6 cases and two of them revealed per portal fibrosis as reported in other studies. ${ }^{10,11}$ The mean duration of the operation time was higher (177.66 minutes) in Choledocho-cholecystoduodenostomy and lower (95.78 minutes) in Hepaticoduodenostomy. One patient in each type $(1 / 9,1 / 14,1 / 3,1 / 6)$ of operation developed an anastomotic leakage. Highest rate of anastomotic leakage observed in Choledocho-cholecysto-duodenostomy (33.3\%) and lowest rate found in Hepatico-duodenostomy (7.1\%). Here significant difference was not found $(p=0.64)$. In our study, there was no mortality. This is in parallel with mortality rate in other studies. ${ }^{12,13}$ There is a reported case of mortality in a patient of Choledocho-cholecysto-duodenostomy where the author mentioned unexplained cause of death without any abdominal signs and symptoms. ${ }^{5}$ In a another study, one late mortality due to liver failure occurred 6 months after Roux-en-Y Hepaticojejunostomy with preoperative severe liver cirrhosis. ${ }^{14}$

\section{Conclusion}

Besides the conventional Roux-en-Y hepatico-jejunostomy, Hepatico-duodenostomy is an acceptable technique in the management of choledocal cyst as it's a simple, quick technique and being more physiological with maintaining normal anatomy in attaining biliary drainage. In addition, it has less bile leak rate and has advantages of early feeding and shorter hospital stay. It also avoids multiple intestinal anastomoses. So, Hepatico-duodenostomy may be the choice of options. Other techniques may be the alternative options in future but need a prospective, randomized controlled trial and long term follow up with a large series of patients.

\section{Acknowledgments}

None.

\section{Conflicts of interest}

The authors declare that there are no conflicts of interest.

\section{Funding}

None.

\section{References}

1. Congo K, Lopes MF, Oliveira PH, et al. Outcomes of choledochal cysts with or without intrahepatic involvement in children after extrahepatic cyst excision and Roux-en-Y hepaticojejunostomy. Ann Hepatol. 2012;11(4):536-543.

2. Sathyanarayana KV, Mummaneni SA. Comparative study of hepaticoduodenostomy Vs. hepatico-jejunostomy surgical procedures in the management of choledochal cyst in children. IAIM. 2018;5(10):127-137.

3. Saxena NA, Kulkarni BK, Borwankar SS, et al. Hepaticoduodenostomy as a technique for biliary anastomosis in children with choledochal cyst: an experience with 31 cases. Ann Pediatr Surg. 2017;13(2):78-80.

4. Tello de Meneses SA, Riggen ML, Orozco CEG. Type I choledocal cyst: Imaging diagnosis and hepaticoduodenostomy as a therapeutic measure. Bol Med Hosp Infant Mex. 2013;70(6):479-483.

5. Hoque S. A new surgical technique of biliary drainage. IJCM. 2013;4:400 404.

6. Felder SI, Menon VG, Nissen NN, et al. Hepaticojejunostomy using short-limb Roux-en-Y reconstruction. JAMA Surg. 2013;148(3):253-257.

7. Saing H, Han H, Chan KL, et al. Early and late results of excision of choledochal cysts. J Pediatr Surg. 1997;32(11):1563-1566.

8. Li Z, Cui N, Chen L. Treatment experience of subsequent complications after Roux-en-Y biliojejunostomy. Eur Surg Res. 2009;43(1):34-38.

9. Patil V, Kanetkar V, Talpallikar MC. Hepaticoduodenostomy for biliary reconstruction after surgical resection of choledochal cyst: a 25-year experience. Indian J Surg. 2015;77(Suppl 2):240-244.

10. Mukhopadhyay B, Shukla RM, Mukhopadhyay M, et al. Choledochal cyst: A review of 79 cases and the role of hepaticodochoduodenostomy. $J$ Indian Assoc Pediatr Surg. 2011;16(2):54-57.

11. Büyükyavuz I, Ekinci S, Ciftçi AO, et al. A retrospective study of choledochal cyst: clinical presentation, diagnosis and treatment. Turk $J$ Pediatr. 2003;45(4):321-325.

12. Shimotakahara A, Yamataka A, Yanai $T$, et al. Roux-en-Y hepaticojejunostomy or hepaticoduodenostomy for biliary reconstruction during the surgical treatment of choledochal cyst: Which is better? Pediatr Surg Int. 2005;21(1):5-7.

13. Yamataka A, Ohshiro K, Okada Y, et al. Complications after cyst excision with hepaticoenterostomy for choledochal cysts and their surgical management in children versus adults. J Pediatr Surg. 1997;32(7):10971102 .

14. Elhalaby E, Hashish A, Elbarbary M, et al. Roux-en-Y hepaticojejunostomy versus hepaticodudenostmy for biliary reconstruction after excision of choledochal cysts in children. Ann Pediatr Surg. 2005;1(1):79-85. 